\title{
The Generations at Work in Puerto Rico: A View From Industrial- Organizational Psychology and the Development Stages
}

\author{
Alondra del Valle Lago \\ Intelligence Forecasting, Corp. \\ Miguel Martínez-Lugo \\ Carlos Albizu University \\ Ramón Rodríguez Montalbán \\ Carlos Albizu University
}

\begin{abstract}
The purpose of this study is to determine whether there are truly generational and/or stage of development differences concerning the variables of meaning of work, motivation, work centrality, and intention to quit. The sample was composed of 948 participants from different workplaces in Puerto Rico. Regarding the generation to which the participants belong, $7.3 \%(n=69)$ belong to the Baby Boomers generation, 30.9\% $(n=293)$ belong to generation X, and finally, $61.8 \%$ belong to the Millennial generation. In terms of stages of development, $68 \%$ ( $n=653)$ of the participants belong to the early adulthood stage, $28.5 \%(n=270)$ of the participants belong to the middle adulthood stage, and $2.6 \%(n=25)$ of the participants belong to the older adulthood stage. There were significant differences according to generations in centrality and intention to quit variables. There were significant differences by stage of development between the centrality, motivation, and intention to quit variables. No significant differences were found for the meaning of work variable by generations or by stage of development.
\end{abstract}

Keywords: generations, stages of development, organizational variables

\section{INTRODUCTION}

In recent years, popular literature publishes and markets the need to be able to understand, differentiate, and accommodate the different generations in the workplace today (Bretcon, Walker \& Jones-Farmer, 2014; Stark, 2017). These alleged differences only describe conglomerate characteristics of each generation which are creating "conflicts" in workplaces in different industries in terms of management, administration, supervision and work, leadership and communication styles, among other organizational variables (Costanza, Badger, Fraser, Severt \& Gade, 2012; Zemke, Raines, Filipczack, 2000). One possible consideration in this regard is that misunderstandings and generalizations may be occurring in the workplace about diversity by age, life stage, personality type, or individual differences, job and/or career expectations (Deal, 2007). 
Campbell, Twenge and Campbell (2017) state that, given the controversy and discrepancy between the popular and scientific literature, it is necessary to think twice about whether the term generation is truly a useful social construct capable of establishing clear limits regarding the differences that each generational group may have. These authors indicate that the perspective when studying generations should be multidimensional since other factors such as culture, history and generational identification have, at least theoretically, a greater impact on how a generation will be educated. These factors create a constant flow of change in terms of the attitudes, values and personality traits that an individual may develop according to the historical and cultural context in which he/she finds him/herself.

\section{Generations at Work}

The phenomenon of generations in the context of work brings a competition culture and an "us versus them" culture (Zemke et al., 2000). This, in turn, generates several conflicts as a result of a clash of principles, values, ethics and personality in terms of how to work. Zemke et al. state that, in the face of this generational diversity in the workplace, organizations should value and perceive the generational differences found among their employees as strengths. However, this is answered by the study of Bretcon et al. (2014) where it is discussed that organizations should be cautious in implementing strategies in the organizational processes of recruitment, selection, training, promotion, and performance evaluation to accommodate the needs of the different generations in the workplace, as this could accidentally lead to age discrimination. For Campbell, Twenge and Campbell (2017) this caution arises from the fact that the scientific evidence provided to support such strategies based on generational differences is dissenting, as it could be emerging from cross-sectional studies that may not necessarily be replicable or extendable given that they are studies that occur and are measured once in time.

It is also important to consider that this emphasis on generations arises mostly in the United States. The replicability of generational characteristics in organizational contexts of different countries created under the U.S. context will only be limited to the superficiality of population trends and not to the historical, cultural and global analysis that the results of a country's social change and movements may have. The following is a description of the different generations.

\section{Baby Boomers in the Workplace}

Something distinctive about this generation is that it is argued that they seek jobs where they are offered opportunities for growth within the same company, creating a sense of loyalty to it, so they rarely change or leave their job frequently (Howe et al., 2007 Lancaster et al., 2002; Strauss \& Howe, 1991; Zemke et al., 2000;). According to Lancaster et al. (2002) Baby Boomers are interested in having a career where they are challenged, where, upon their completion, they become opportunities that lead to visible recognition and to face and overcome new work challenges. However, it is important to highlight that this sense of loyalty will not necessarily mean that they are passionate about or feel a sense of meaning about the work they do (Lancaster et al., 2002).

\section{Generation $X$ in the Workplace}

Members of this generation are extremely skillful, resourceful and independent and rely on themselves and their peers to achieve the work goals they have set for themselves (Zemke et al., 2002). This generation understands that having a job is not a guarantee of stability or economic security, since at any moment and without any warning they could lose their job (Zemke et al., 2002). Therefore, they will not necessarily have a strong sense of centrality in their work, given the need for balance and disconnection from work after completing their daily tasks (Zemke et al., 2000; Lancaster et al., 2002). An important factor that can motivate individuals of this generation is when a company decides to invest in the higher education of its employees, since in this way members of this generation can generate a repertoire of knowledge, skills and experiences that gives them a sense of preparation for the future. In terms of changing jobs and intention to quit, this generation is described as the most likely to be moving from job to job (Zemke et al.; 2000, Lancaster et al.; 2002). 


\section{Millennials in the Workplace}

This generational group builds a parallel career, as they are able to have several jobs at the same time and can perform them satisfactorily (Lancaster, et al., 2002). In addition, they are described as optimistic about the future, but with a realistic view of the present, they know how to combine teamwork, the use of technology and the integration of positive attitudes to help them achieve their goals (Zemke et al., 2000). On the other hand, Strauss and Howe (1991) indicate that Millenials are known for promoting civic values among the community and restructuring social institutions for the common good. They are also described as resilient, dedicated to work and aware of sacrificing their personal interests to work for the collective good (Zemke et al., 2000).

\section{Generational Differences and Similarities in the Work Context}

Some studies show that generations differ from each other regarding the context of work. Ertas (2015) found that, compared to other generations, Millenials were five times more likely to be dissatisfied with their jobs and consider leaving their job, location and industry. Martínez, Rodríguez and Vargas (2003) explored the differences and similarities between Baby Boomers and Generation X in the work area in Puerto Rico. The variables measured in this study were: organizational commitment, job satisfaction, level of employee involvement at work, organizational frustration, flexibility and adaptation to change, willingness to learn, unemployment history, core life interests, and retirement planning. The results indicate that the generations studied did not differ significantly from each other regarding the study variables (Martinez et. al., 2003), on the contrary, they observed that these generations mostly converged. In another study, Sepulveda-Nichols (2000) examined the differences in personality traits between workers of the Baby Boomers and Generation X. The findings of the study show that the similarities between Baby Boomers and Generation $\mathrm{X}$ are greater than the differences, as the differences between personality traits could be found more by gender and age than by belonging to any of the generations under study.

\section{Stages of Human Development}

An approach to consider when studying differences in attitudes, values or opinions related to work is to give more attention to a person's stage of human development than to his or her generational status. This is because beyond the fact that a person is classified under a generation due to their year of birth, the stage of development they are in can provide us with a deeper insight into the psychological processes they are going through in their life. This means that the stages of human development are capable of explaining the changes that a person experiences in his or her world view, virtues, beliefs and values (Arnett, 2000; Erikson, 1968). Likewise, for many adults, work is often a primary source of a sense of purpose where work-related activities are performed (Willis \& Reid, 1999). In accordance with the authors, work is the way in which the adult is integrated and recognized as a member of a larger community. Thus, the development of adulthood is characterized by variation in experiences and attitudes from person to person (Willis \& Reid, 1999). For the purposes of this study, when talking about stages of development, we refer to the stages of early adulthood, middle adulthood and older adulthood.

\section{Early Adulthood}

This stage ranges from 18 years old to approximately 40 years old. At this stage, individuals are in a continuous flux of change on their way to adulthood. It is also characterized as a period in which people try to understand their role in the context of work, interpersonal relationships, among other areas (Erickson, 1968; Arnett, 2000; Super, 1957; 1986).

\section{Middle Adulthood}

This stage ranges from 40 years old to approximately 65 years old. This stage is defined by a process of reflection on the legacy that the person wants to leave in the world, whether through his or her family, work or community. They are also ensuring job security, ensuring satisfactory and competent performance, and taking advantage of growth opportunities as they arise. They also seek to fulfill the expectations of their 
position, stay informed and updated regarding the innovation of processes and technologies necessary for their work routine (Erickson, 1968; Arnett, 2000; Super, 1957;1986).

\section{Older Adulthood}

This stage begins at 65 years old and ends with the death of the person. At this stage, the achievements made throughout their life trajectory are usually contemplated. It generates a feeling of uniqueness, acceptance and coherence in terms of the experiences that have been lived. In the work environment they often go through a slowdown from the work flow they managed when they were young on their way to retirement (Erickson, 1968; Arnett, 2000; Super, 1957;1986).

There are several investigations on occupational variables and their manifestation in the stages of development. Martínez-Lugo, Méndez Collada and Maeso Flores (1999) performed a study on the work centrality and central life interests, where they compared two groups: young and old. In terms of work centrality, the group of aged employees obtained higher scores than that of younger employees. Also, it was noted that as age increased, the average score on the work centrality variable also increased.

The studies presented illustrate how the stages of human development generate progressive changes in relation to the attitudes, thoughts and behaviors that a person may have throughout his or her career. This means that individuals will gain new perspectives on the dimensions of their lives as they go through the different stages of development (Arnett, 2000; 2015). Therefore, it is possible that they could be observed in the workplace in terms of how people of different ages show that they feel motivated, give a degree of meaning to their work, understand how central the work is, and would consider changing jobs or careers.

\section{Intrinsic Motivation}

The workplace is one of the main contexts in which motivation is examined, due to the results that a person may or may not produce in the workplace. Intrinsic motivation refers to when a person feels inspired to do something. Therefore, all their energy will be directed toward completing some activity or goal (Deci \& Ryan, 2000). According to Amabile (1993) a person who is intrinsically motivated with his or her work will tend to produce high quality work, be persistent, creative and willing to collaborate.

\section{Meaning of Work}

The meaning of work refers to how people make or find positive meaning in the work they are doing, even if it is not very desirable (Wrzesnieski, 2003). This meaning can arise from experiences, interactions, and the interpretations a person provides to the work he or she performs (Rosso, Dekas \& Wrzesnieski, 2010). Therefore, meaning provides a starting point for the person about the expectations he or she can form based on this collection of beliefs, values and experiences (MOW, 1987).

\section{Work Centrality}

Centrality refers to the degree of importance people attach to their jobs at any point in time (MOW, 1987; Paullay, Alliger and Stone-Romero 1994; Sharabi \& Harpaz, 2010). In turn, this is divided into two parts; one relative and the other absolute (Sharabi et al., 2010). Relative work centrality refers to when a person compares the importance of his or her work with other areas of his or her life (i.e. family). While absolute work centrality refers to the meaning and importance that the person gives to work.

\section{Intention to Quit}

The intention to quit arises from the likelihood that a person may decide to change jobs in a given time either career or workplace (Kaur, Mohindru, \& Pankaj, 2013). Kaur et al. (2013) indicate that there are demographic variables such as age, gender, education, years of experience, among others that can serve as indicators of intention to quit.

Based on the information provided, there is a need to know how the variables of intrinsic motivation, work meaning, work centrality and intention to quit differ or are similar in a sample of employees in Puerto Rico. The research question that leads this study is the following: Are there generational differences that 
are influencing motivation, work meaning, centrality and intention to quit in a group of employees in Puerto Rico? To answer this question, the following hypotheses were generated:

Hypothesis 1. There will be statistically significant differences in motivation according to the generation to which the research participant belongs to (Baby Boomer, X or Millennial).

Hypothesis 2. There will be statistically significant differences regarding the meaning of work variable according to the generation the research participant belongs to (Baby Boomer, X or Millennial).

Hypothesis 3. There will be statistically significant differences regarding the work centrality according to the generation the research participant belongs to (Baby Boomer, X or Millennial).

Hypothesis 4. There will be statistically significant differences in the intention to quit according to the generation to which the research participant belongs to (Baby Boomer, X or Millennial).

\section{Justification}

The studies described here are some examples of empirical research regarding the differences and/or similarities that may exist between different generations in a work context. However, it is necessary to clarify that generations are not considered a psychological phenomenon. It should also be emphasized that the stages of development theories provide a broad explanation of the psychosocial phenomena that a human being may go through according to the different stages. Due to this, there is a need to reflect and investigate whether the model of the stages of human development could describe and/or explain the behaviors of people in the work context, and whether they are indeed different or similar in terms of some organizational variables, such as intrinsic motivation, meaning of work, work centrality and intention to quit. These variables were selected because the outcomes of behaviors arising from these can positively or negatively impact an organization's performance and productivity (Amabile, 1993; Deci \& Ryan, 2000; Kaur, et al., 2015; MOW, 1987; Pérez González \& Díaz, 2005; Velando, 2004).

\section{METHOD}

\section{Participants}

The final sample for this study was composed of 948 participants. Their ages ranged from 21 years old to 70 years old $(M=36.02, D E=10.97) .65 .4 \%$ of the participants were women and $34.6 \%$ were men. $78.3 \%$ indicated that they were employed full-time. The sector for which the most people work is the service sector (22.6\%). Years working ranged from 0 to 54 years old $(M=36.02, D E=10.97)$. In terms of academic preparation, $40 \%$ indicated that they have a bachelor's degree. $28.5 \%$ stated that they performed supervisory tasks. Regarding the generation to which the participants belong, $7.3 \%(n=69)$ belong to the Baby Boomers generation, $30.9 \%(n=293)$ belong to generation $X$, and finally, $61.8 \%$ belong to the Millennial generation. In terms of stages of development, 68\% ( $n=653)$ of the participants belong to the early adulthood stage, $28.5 \%(n=270)$ of the participants belong to the middle adulthood stage, and $2.6 \%(n=25)$ of the participants belong to the older adulthood stage.

\section{Tools}

\section{Demographic Data Sheet}

The general data questionnaire requested information regarding gender, age, educational background, number of years working, the type of organization where you work, the industry sector for which you work, whether you are in a supervisory role, and the type of working day you perform (whether full-time or parttime). 


\section{Intrinsic Motivation Scale}

The Situational Motivation Scale (SIMS) Intrinsic Motivation ub-scale of Guay, Vallerand and Blanchard (2000) consists of four items that are answered on a seven-anchor Likert-type scale ranging from 1 (completely disagree) to 7 (completely agree). The items in this scale provide a reason why a person performs the job. An example of an item would be, "Because I feel well fulfilled." This sub-scale has a Cronbach's $\alpha$ internal consistency value of .95 .

\section{Brief Work Centrality Scale}

The work centrality scale of Martínez-Lugo, Rodríguez-Montalbán and Andújar (2015) consists of eight items that are answered in a seven-anchor Likert-type response format ranging from 1 (completely disagree) to 7 (completely agree). The items of this scale display the importance that a person attributes to work. An example of an item on this scale is "Working defines me as a person". This scale has a Cronbach's $\alpha$ internal consistency value of .87 .

\section{Scale of Meaning of Work}

The Task Meaning Scale by Rodríguez Montalbán, Martínez Lugo and Sánchez Cardona (2015) consists of three items answered on a Likert-type scale with seven response anchors ranging from 0 (completely disagree) to 6 (completely agree). The items on this scale represent the meaning that a person has developed towards work. An example of an item is, "My work significantly affects the lives of other people within the organization". This scale has a Cronbach's $\alpha$ internal consistency value of .75.

\section{Intention-to-Quit Scale}

The Intention to Quit Scale by Rodríguez-Montalbán, Sánchez and Martínez Lugo (2014), consists of four items answered on a Likert-type scale with seven response anchors ranging from 0 (completely disagree) to 6 (completely agree). The items of this scale provide reasons why a person would think about quitting a job. An example of an item is, "If I had another job offer, I would leave this company". This scale has a Cronbach's $\alpha$ internal consistency value of .93.

\section{General Procedures}

Secondary data analysis was performed for this study. These come from research conducted by Rodríguez-Montalbán, Martínez-Lugo, Ortega-Santori, del Valle-Lago, Rosario-Rodríguez, GómezCaicedo, Vázquez, González, Rivera and Serrano (2016). Permission was requested from the principal investigators to conduct a secondary data study. This research was approved by the institutional ethics review board of Carlos Albizu University, which protects the rights of participants. Participants were guaranteed their rights of voluntariness, anonymity, confidentiality and the right to leave the studies at any time they wished.

In order to fulfill the research purpose, the transformations from the age variable to the generation variable and from the age variable to the stage of development variable were carried out. This was done by taking into consideration the age reported by the participants at the time of their participation in the primary research and then they were categorized under the corresponding generation and stage of development.

\section{RESULTS}

Descriptive analyses were performed for the study variables, as well as normal distribution analyses in order to identify the type of statistical test that would be used for the statistical analysis. Normality analyses were also performed, using the Shapiro-Wilks test to determine whether the variables were normally distributed. In this case the Shapiro-Wilks normality tests showed that for the four variables under study the data do not fit a normal distribution in terms of generational affiliation. For the intrinsic motivation variable the results indicate that this is not normally distributed for the Baby Boomers $D(59)=0.917, \mathrm{p}<$ .001 , Generation X D $(263)=0.969, \mathrm{p}<.001$, and the Millennial generation $D(566)=0.962, \mathrm{p}<.001$. On the other hand, this test also indicated that the data were not normally distributed for the meaning of work 
variable for the generation Baby Boomers $D(63)=0.833, \mathrm{p}<.001$ Generation X $D(286)=0.962, \mathrm{p}<.001$, and the Millennials $D(584)=0.971, \mathrm{p}<.001$.Also, this test indicated that the data were not normally distributed for the work centrality variable with respect to the generation Baby Boomers D $(61)=0.962, \mathrm{p}$ $<.001$, Generation X D (286) $=0.991, \mathrm{p}<.001$, and Millennials $D(576)=0.985, p<.001$. Finally, this test indicated that the data were not normally distributed for the quit intention variable for the generation Baby Boomers $D(64)=0.919, p<.001$, Generation $X \mathrm{D}(288)=0.953, p<.001$, and Millennial $D(583)$ $=0.970, p<.001$. Therefore, the Kruskal Wallis $H$-statistic test for nonparametric data was used in order to compare the rank averages and test the hypotheses. The following are the results for each study hypothesis.

For Hypothesis 1, the results of the Kruskal Wallis $H$-test reveal that there are no significant differences in the levels of intrinsic motivation $H(2)=3.96, \mathrm{p}=.138, \eta^{2}=.002$, Baby Boomers ( $\mathrm{M}$ range $=4.50$ ), Generation X (M range $=4.30)$ and Millenials ( $\mathrm{M}$ range $=4.36)$. In order to test Hypothesis 2, Kruskal Wallis analysis was performed and it was found that there are no significant differences in the levels of meaning of work $H(2)=.797, p=.671, \eta^{2}=-.001$, Baby Boomers $(M$ range $=4.64)$, Generation X $(M$ range $=4.76)$ and Millenials $(M$ range $=4.67$ ). In order to test Hypothesis 3, Kruskal Wallis analysis was performed and it was found that there are significant differences in the levels of work centrality $H(2)=$ $13.07, p=.001, \eta^{2}=.011$, Baby Boomers $(M$ range $=4.34)$, Generation X $(M$ range $=3.70)$ and Millenials $(M$ range $=3.62)$. Post hoc analyses for the Kruskal Wallis test show that differences are found between the Baby Boomer group and Millenials $(p=.001)$ and between the Baby Boomer group and Generation X $(p=.010)$.

In order to test Hypothesis 4, Kruskal Wallis analysis was performed and it was found that there are significant differences in the levels of intention to quit $H(2)=52.77, p=.000, \eta^{2}=.053$, Baby Boomers $(M$ range $=1.86)$, Generation X $(M$ range $=2.53)$ and Millenials $(M$ range $=3.30)$. Post hoc analyses for the Kruskal Wallis test show that differences are found between the Baby Boomer group and Generation $\mathrm{X}$ $(p=.037)$ and between the Baby Boomers group and Millenials $(p=.000)$, and between the Generation $\mathrm{X}$ group and Millenials $(p=.000)$.

\section{Subsequent Analysis}

The results of the proposed research hypotheses show that there are both similarities and differences between the generations. As part of an additional analysis, we proceeded to explore differences among the variables by stage of development. For this purpose, the variable age was transformed into the variable stage of development, and each participant was categorized under the corresponding stage.

This is because developmental theories allow for a more powerful theoretical framework in order to explain the differences between groups and could help to effectively explore more deeply how the outcomes of psychosocial experiences may influence the way a person constructs his/her work view, particularly intrinsic motivation, work meaning, work centrality, and intention to quit (Alcover \& Topa, ; 2018; Dycthwald, et al. ; 2006; Martinez, et al.; 1999; Super, 1986; Willis \& Reid, 1999,). Therefore, when investigating this issue, it was decided to evaluate whether there are significant differences according to the stages of development in the variables of motivation, meaning, centrality and intention to quit. For this, normality analyses were also performed, using the Shapiro-Wilks test to determine whether the variables were normally distributed. The results reveal that for the four variables under study the data do not fit a normal distribution in terms of stage of development. For the intrinsic motivation variable the results indicate that this is not normally distributed for the stage of development of early adulthood $D(628)=$ $0.963, p<.001$, middle adulthood $D(242)=0.952, p<.001$, and older adulthood $D(18)=0.962, p<.001$. Likewise, this test also stated that the data were not normally distributed for the meaning of work variable for the stage of development of early adulthood $D(651)=0.971, p<.000$, middle adulthood $D(262)=$ $0.949, p<.000$, and older adulthood $D(20)=0.906, p<.000$. For the work centrality variable the results state that it is not normally distributed for the group early adulthood stage of development $D(642)=0.985$, $p<.005$, middle adulthood $D(262)=0.987, p<.000$, and older adulthood $D(19)=0.954, p<.001$. For the intention to quit variable the results state that it is not normally distributed for the group early adulthood stage of development $D(649)=0.968, p<.000$, middle adulthood $D(265)=0.954, p<.000$, and older 
adulthood $D(21)=0.874, p<.001$. Therefore, the Kruskal-Wallis nonparametric $H$ test and the corresponding effect size analysis were performed for the study variables.

In order to explore whether there are differences between intrinsic motivation by stage of development, Kruskal Wallis analysis was performed and it was found that there are significant differences in the levels of intrinsic motivation $H(2)=.608, p=.738, \eta^{2}=.001$, the stage of development of early adulthood $(M$ range $=4.35)$, middle adulthood $(M$ range $=4.33)$ and older adulthood $(M$ range $=4.88)$. Post hoc analyses for the Kruskal Wallis test show that differences are found between the early adulthood and older adulthood group $(p=.009$, and also, between the middle adulthood and older adulthood developmental stage group $(p=.006)$. For the meaning of work variable, Kruskal Wallis analysis was performed and found that there are no significant differences in the levels of meaning of work $H(2)=.608, p=.738 \eta^{2}=.001$, the stage of development of early adulthood $(M$ range $=4.68)$, middle adulthood $(M$ range $=4.74)$ and older adulthood $(M$ range $=4.51)$.

Likewise, in order to explore whether there are differences in the levels of work centrality by stages of development, a Kruskal Wallis analysis was performed and it was found that there are significant differences in the levels of work centrality $H(2)=14.53, p=.001 \eta^{2}=.013$, the stage of development of early adulthood $(M$ range $=3.62)$, middle adulthood $(M$ range $=3.77)$ and older adulthood $(M$ range $=4.90)$. Post hoc analyses for the Kruskal Wallis test show that differences are found between the early adulthood group and older adulthood $(p=.001)$ and between the middle adulthood group and older adulthood $\mathrm{x}(p=$ .007). Finally, in order to explore whether there are differences between the intention to quit and the stages of development, a Kruskal Wallis analysis was performed and it was found that there are significant differences in the levels of intention to quit $H(2)=52.66, p=.000 . \eta^{2}=.05$, the stage of development of early adulthood ( $M$ range $=3.27)$, middle adulthood $(M$ range $=2.33)$ and older adulthood $(M$ range $=1.64)$. Post hoc analyses for the Kruskal Wallis test show that differences are found between the early adulthood group and older adulthood $(p=.000)$ and between the middle adulthood group and older adulthood $\mathrm{x}(p=$ $.000)$.

\section{CONCLUSION}

The purpose of this study was to analyze whether there were differences between Baby Boomers, X and Millenials in the organizational variables of intrinsic motivation, meaning of work, work centrality and intention to quit. The results reveal that, on the work centrality variables, Baby Boomers obtained higher scores than Generation X and Millenials. On the intention to quit variable, the Millennial generation scored significantly higher, followed by Generation X and Baby Boomers. In general, it was noted that there were statistically significant differences in the organizational variables under study, both in the stages of development and among the generations.

In both analyses (by generation and stage of development) no statistically significant differences were found in the levels of meaning developed and attributed to work. This can be explained by the fact that identifying and exercising with purpose and, therefore, providing meaning to what we do inside or outside of work is necessary for human beings to be able to move towards self-fulfillment, to feel value, progress, recognition and, above all, that they are contributing to the environment in which they are playing a role (MOW, 1987). This is congruent with the study by Weeks and Schaffert (2017) where when studying how people assigned meaning to work, the results were similar across participant ages.

Regarding the findings on intrinsic motivation, the results show that there are no significant differences by generational group. In other words, the way in which Baby Boomers, $\mathrm{X}$ and Millenials feel motivated or unmotivated may be manifested more by individual aspects of the work context to which they belong than by the generation to which they belong. This is in line with Deci and Ryan's (2000) self-determination theory and the study by Locke and Latham (2004), both of which state that fluctuations in the levels of motivation that a person may feel at any given time will be determined exclusively by the goal that the person wants to achieve and the skills that he/she can use to do so. Therefore, as a person moves toward his/her goal, he/she may feel jointly extrinsically and intrinsically motivated. Likewise, this contradicts what has been postulated by other authors (Lancaster et al. 2002; Zemke et al., 2000) who show that the 
generations will be motivated by different reasons. However, when examining how motivation might differ by stages of human development, significant differences were found between middle adulthood and older adulthood and also between early adulthood and older adulthood. These differences can be explained by the developmental theory perspective of Erikson (1968), which indicates that the person in the stage of older adulthood is making an evaluative judgment on the achievements attained up to the current time and assesses whether these achievements are consistent and satisfactory with what he/she projected to achieve in his/her life.

On the other hand, regarding the findings of work centrality, differences were found between generations concerning the levels of work centrality. These differences are mostly observed between Millennials and Baby Boomers and between Generation X and Baby Boomers. This could be explained by how each person values his/her work, either relatively or absolutely (Pérez-González \& Díaz, 2005). Similarly, in terms of findings by stage of development, a similar pattern is repeated in terms of differences by work centrality. Differences are evident between early adulthood and older adulthood and between middle adulthood and older adulthood. This may be because depending on the stage of development in which the person is, he/she will give a greater or lesser level of centrality to his/her work and other areas of interest in his/her life. Also Arnett (2015) and Erikson (1968) discuss how in the stages of emerging adulthood and early adulthood an exploration often occurs in terms of identity, intimacy bonds, and roles they may assume and exercise depending on the transition from one stage to another that the person is in. They will also be influenced by the perceived value attached to cultural norms, beliefs, sense of responsibility, commitment and expectations that a person has about his/her work. This is consistent with the study by Martinez et. al (1999) where they found that the older the age, the higher the score obtained on the work centrality scale.

On the other hand, regarding the findings of intention to quit, there are differences both by generations and by stages of development. The differences between the generations are reflected in the three groups Baby Boomers, X and Millenials. According to Kaur et al. (2013) this may be due to the fact that age is one of the indicators that can serve as a predictor for this variable, given that the older an employee is, the less likely he/she is to entertain the thought of moving to another workplace. Similarly, Lancaster et al. (2002) report that a sense of security can influence these groups and lead to career or job movement. This is in line with other studies (see Ertas, 2015). Furthermore, regarding the findings of intention to quit by stage of development, the differences are observed between early adulthood and older adulthood and between middle adulthood and older adulthood. This may be due to the fact that in early adulthood the need for exploration arises regarding the dimensions that are part of the person's identity and this could drive him/her to consider experimenting different career opportunities or workplaces until he/she finds the one that provides satisfaction and aligns with his/her identity and belief system (Arnett, 2015; Erikson, 1968; Kaur et al., 2013; Super, 1985). Concerning middle adulthood, the differences observed may be due to the fact that at this stage the person is in search of feeling that he/she is useful and contributes effectively to his/her social environment (Erikson, 1968). Therefore, staying sustainable over time in a career and/or workplace may help him/her to generate and achieve the results he/she expects from his/her social contribution (Super, 1985). This is in line with Kaur et al (2015), who report that the longer a person stays at their workplace the less likely they are to consider leaving it. On the other hand, regarding older adulthood, this difference may be due to the fact that at this stage people may begin to consider or are in the process of making the transition to retirement, therefore, they may not necessarily consider leaving or moving from one career and/or workplace to another (Dychtwald et al.; 2006; Erikson, 1968; Super, 1957).

\section{Practical and Theoretical Implications}

This study provides different contributions at both the theoretical and practical levels. At a theoretical level, it covers the stages of life in which the employee finds him/herself and how, given this stage, cognitions, feelings, emotions and attitudes are generated that may be influencing the work context. In particular, this study shows that differences and similarities were found in the variables intrinsic motivation, meaning of work, work centrality and intention to quit, both between generations and stages of development. 
On a practical level, this study can help develop individual, group and organizational interventions that consider that people will fundamentally expect to have a fulfilling career and to work in an organization where their contribution to the achievement of its goals and results is valued, regardless of the person's age. Therefore, it is not necessary to enter into developing and investing in organizational and operational strategies solely designed to address the particularities of a group based on the generation to which they belong, but rather, taking into consideration the stages of development in which they find themselves.

\section{Strengths and Limitations}

One limitation of this study is that, as it is a secondary data analysis, it is not known whether there is any effect of temporality of the data collected. Also, the sample data were collected by availability, which limits the generalization of findings. However, this study has strengths and contributions for the field of Industrial Organizational Psychology. The first strength is that due to the size of the sample, a diverse participation of employees of different ages was obtained. Likewise, the second strength lies in providing a different view of the variables under study and the generations by presenting the theoretical analysis from the stages of development. This as a more comprehensive view of how psychosocial experience might shape the way a person experiences cognitions, emotions, and behaviors in their career and/or workplace.

In light of the study's findings, it can be concluded that each human being will have his/her own experience and life process that directly or indirectly may be presented in the work environment. It is also necessary to think twice about whether the theoretical model of generations can explain people's experiences in the context of work. On the other hand, a greater focus can be given to the stages of development as a model to explain the similarities and differences that people in a work context may have. This is because the stages of development provide a broad theoretical and referential framework regarding the cognitive, physical, emotional and psychological changes that a person will experience throughout his/her life. In terms of the work context, the stages of development may explain the professional trajectory that a person may have in his/her career.

\section{ACKNOWLEDGEMENT}

Translated \& Edited by American Publishing Services (https://americanpublishingservices.com/).

\section{ENDNOTE}

1. For ease of reading, the authors have chosen to use the masculine gender to refer to people of both genders (male and female).

\section{REFERENCES}

Alcover, C.M., \& Topa, G. (2018) Work characteristics, motivational orientations, psychological work ability and job mobility intentions of older workers. Plos One, 13(4), e0195973. http://doi.org/10.371/journal.pone.0195973

Amabile, T. (1993) Motivational synergy: Toward new conceptualizations of intrinsic and extrinsic motivation in the workplace. Human Resource Management Review, 3(3), 185-201.

Arnett, J.J. (2000). Emerging adulthood: A theory of development from the late teens through the twenties. American Psychologist, 55(5), 469-480. http://dx.doi.org/10.1037/0003-066X.55.5.469

Arnett, J.J. (2015). Emerging adulthood: The winding road from the late teens through the twenties (2nd ed.). New York, NY: Oxford University Press.

Bretcon J.B., Walker H.J., \& Jones-Farmer A. (2014). Generational differences in workplace behavior. Journal of Applied Social Psychology, 44, 175-189. doi: 10.1111/jasp.12208

Campbell, S.M., Twenge, J.M., \& Campbell, W.K. (2017). Fuzzy but useful constructs: Making sense of the differences between generations. Work, Aging and Recruitment, 3(2), 130-139. doi:10.1093/worker/wax001 
Costanza D., Fraser, R., Severt, J., \& Grade, A.P. (2012). Generational differences in work-related attitudes. Journal of Business Psychology, 27, 375-394. doi: 10.1007/s10869-01209259-4

Deal, J. (2007). Retiring the generation gap: How employees young and old can find common ground. John Wiley \& Sons, Inc.: San Francisco, CA.

Deci, E.L., \& Ryan, R.M. (2000). The "what" and "why" of goal pursuits: Human needs and the selfdetermination of behavior. Psychological Inquiry, 11(4), 227-268. http://doi.org/10.1207/S15327965PLI1104_01

Dychtwald, K., Eirckson, T., \& Morison, R. (2006) Workforce crisis. Harvard Business School Press: Boston, MA.

Erikson, E.H. (1968). Identity: Youth and crisis. New York: Norton.

Ertas, N. (2015). Turnover intentions and work motivations of Millennial employees in federal service. Public Personnel Management, 44(3), 401-423. doi: 10.177/0091026015588193

Guay, F., Vallerad, R.J., \& Blanchard, C. (2000). On the assessment of situational intrinsic and extrinsic motivation: The situational motivation scale (SIMS). Motivation and Emotion, 24(3), 175-213.

Howe, N., \& Strauss, W. (2007, July-August). The next 20 years: How customers and workforce attitudes will evolve. Harvard Business Review.

Kaur, B., Mokindru, \& Pankaj. (2013). Antecedents of turnover intentions: A literature review. Global Journal of Management and Business Studies, 3(10), 1219-1230.

Lancaster, L.C., \& Stillman, D. (2002). When generations collide: Who they are, why they clash, how to solve the generational puzzle at work (Kindle Edition). Retrieved from https://www.amazon.com/Kindle-eBooks/

Locke, E., \& Latham, G., (2004) What should we do about motivation theory? Six recommendations for the twenty-first century. Academy of Management Review, 29(3), 388-403.

Martínez-Lugo, M., Andújar-Rojas, C., \& Rodríguez- Montalbán, R. (2015). Escala breve de centralidad del trabajo. Manuscrito no publicado, Programa de Psicología Industrial Organizacional, Universidad Albizu, San Juan, Puerto Rico.

Martínez-Lugo, M., Méndez Collada, V., \& Maeso Flores, R. (1999). La centralidad de trabajo y los intereses centrales de vida en una muestra de empleados jóvenes y envejecidos en Puerto Rico. Revista Puertorriqueña de Psicología, 12, 77-91.

Martínez-Lugo, M., Rodríguez Sánchez, M., \& Vargas Figueroa, J. (2003). Estudio exploratorio de un grupo de miembros de la generación de los baby boomers y de la generación x en el lugar de trabajo en Puerto Rico. Revista Puertorriqueña de Psicología, 14, 181-209.

MOW, International Research Team. (1987). The Meaning of Working. Londres: Academic Press.

Paullay, I.M., Alliger, G.M., \& Stone-Romero, E.F. (1994). Construct validation of two instruments designed to measure job involvement and work centrality. Journal of Applied Psychology, 79(2), 224-228.

Pérezgonzález, J.D., \& Díaz Vilela, L. (2005). La centralidad del trabajo. Lulu, Inc.: USA.

Rodríguez-Montalbán, R., Martínez-Lugo, M., \& Sánchez- Cardona, I. (2015). Escala del significado de la tarea. Manuscrito no publicado, Programa de Psicología Industrial Organizacional, Universidad Albizu, San Juan, Puerto Rico.

Rodríguez-Montalbán, R., Sánchez-Cardona, I., \& Martínez-Lugo, M. (2014). Escala de Intención de Abandono. Manuscrito no publicado. Universidad Carlos Albizu.

Rosso, B., Dekas, K., \& Wrzesniewski, A. (2010). On the meaning of work: A theoretical integration and review. Research in Organizational Behavior, 30, 91-127.

Sepulveda-Nichols, M. (2004). Diferencias en rasgos de personalidad entre trabajadores de la generación de los baby boomers y trabajadores de la generación x en puerto rico (Disertación doctoral inedita). Universidad Carlos Albizu, San Juan, Puerto Rico.

Sharabi, M., \& Harpaz, I. (2010). Improving employees' work centrality improves organizational performance: Work events and work centrality relationships. Human Resource Development International, 13(4), 379-392. 
Stark, E. (2017). Workplace Differences among intergenerational cohorts: A demonstrable concern for management? The Journal of Applied Management \& Entrepreneurship, 22(1), 1-25.

Strauss, W., \& Howe, N. (1991). Generations: The history of America's future, 1584 to 2069. Harper Perennial: New York, NY.

Super, D.E. (1957). The psychology of careers. Harper \& Row: New York, NY.

Super, D.E. (1985). Coming of age in middle town: Careers in the making. American Psychologists, 40, 405-414.

Weeks, K.P., \& Schaffert, C. (2017). Generational differences in definitions of meaningful work: A mixed methods study. Journal of Business Ethics, pp. 1-17. https://doi.org/10.1007/s10551-017$3621-4$

Willis, S., \& Reid, J.(1999) Life in the middle. Academic Press: San Diego, CA.

Wrzesniewski, A. (2003). Finding positive meaning in work. In K.S. Cameron, J.E. Dutton, \& R.E. Quinn (Eds.), Positive organizational scholarship: Foundations of a new discipline (pp. 296-308). San Francisco, CA.

Zemke, R., Raines, C., \& Filipczak, B. (2000). Generations at work. New York, NY 